\title{
Penile length and somatometric parameters: a study in healthy young Turkish men
}

\begin{abstract}
Yılmaz Aslan ${ }^{1}$, Ali Atan ${ }^{1}$, Ali Ömur Aydın ${ }^{1}$, Varol Nalçacıoğlu ${ }^{1}$, Altug Tuncel ${ }^{1}$ and Ateş Kadığlu ${ }^{2}$
The purpose of this study was to determine average penile length and to investigate the relationship between penile length and somatometric parameters in a group of young, healthy Turkish men. A total of 1132 men were included in the study. The age, height and weight of the subjects were recorded. Penile length was measured in both flaccid and stretched states. The correlation between penile length and somatometric parameters was analysed. The mean age of the subjects was $20.3 \pm 0.9$ years. The mean penile length in flaccid and stretched states was $9.3 \pm 1.3$ and $13.7 \pm 1.6 \mathrm{~cm}$, respectively $(P<0.001)$. There was a positive correlation between flaccid and stretched penile length $(r=0.800, P<0.001)$. The mean testicular volume was $22.0 \pm 2.8 \mathrm{~cm}^{3}$. A weak positive correlation was detected between penile length and mean testicular volume $(r=0.143$ for flaccid penile length and $r=0.140$ for stretched penile length, $\boldsymbol{P}<0.001$ for both). Similarly, weak positive correlations were found between penile length (both flaccid and stretched) and height, weight and body mass index, respectively $(\boldsymbol{P}<0.001$, for all). These results demonstrate that somatometric parameters are correlated with penile length. We believe that further studies would provide more information about the causal relationship.
\end{abstract} Asian Journal of Andrology (2011) 13, 339-341; doi:10.1038/aja.2010.109; published online 13 December 2010

Keywords: orchidometer; penile length; somatometric parameters; testicular volume

\section{INTRODUCTION}

Human penis size refers to the length and width of human male genitalia. Throughout history, penis size has been a mystical topic and a common subject of art work, even represented in artwork by prehistoric cave dwellers. In addition, various phallus-shaped posts were often created by inhabitants of ancient Greece, Rome and Turkey. ${ }^{1}$

Today, increasing numbers of men complain about their penile size and see urologists daily. ${ }^{2}$ It is important to recognize this condition before planning any medical or surgical intervention for penis size.,

Several studies have investigated penile length and its relationship with somatometric parameters such as height, weight, body mass index (BMI), waist/hip ratio, index finger length and shoe size. ${ }^{5-8}$ In the current literature, only one report has investigated penile length and testicular volume in young men. ${ }^{8}$

The aim of this study was to determine the average penile length and to investigate the relationship between penile length and somatometric parameters in a group of healthy, young Turkish men.

\section{MATERIALS AND METHODS}

A group of 1132 healthy Turkish men-military recruits aged 19-30 years-were enrolled in the study between September 2008 and February 2009. All males were Caucasian and circumcised. Men with a history of penile and/or testicular pathology (e.g., Peyronie's disease, penile curvature, orchiopexy and varicocelectomy) were excluded from the study. The age, height and weight of participants were recorded. BMI was computed as the ratio of weight to the square of height $\left(\mathrm{kg} \mathrm{m}^{-2}\right)$. The study was approved by the Institutional Review
Board of Ankara Numune Research and Training Hospital and all subjects provided proper informed consent.

All measurements were performed during military service by the same examiner (YA) to reduce interobserver error and under similar environmental conditions to avoid natural variability in size due to temporal factors such as time of day, room temperature and unreliability of measurement methods. ${ }^{9}$ Measurement, as opposed to self-report, was preferred due to the unreliable nature of self-reporting; men tend to report a larger than accurate penis size. Although there is no standard technique for penile length measurement, the researchers preferred a technique that has been described previously by Wessells et al. ${ }^{10}$

Penile measurements were performed between 10:00 a.m. and 4:00 p.m. under ambient light and room temperature with subjects standing up and with the penis held parallel to the floor. Penile length was measured by a ruler with millimetre markings along the dorsum of the penis from the pubopenile junction to the tip of the glans (meatus) and while under maximal, but not painful, extension. The measurement was performed during both flaccid and stretched states. Testicular volume of the subjects was measured by bimanual palpation using a Prader orchidometer with volumes ranging from 1 to $25 \mathrm{~cm}^{3}$ $\left(1-6,8,10,12,15,20\right.$ and $\left.25 \mathrm{~cm}^{3}\right)$ after simultaneously stretching the scrotal skin over the testis. Testicular volumes between 15 and $25 \mathrm{~cm}^{3}$ were considered within the normal range. ${ }^{11}$

SPSS for Windows version 13.0 (SPSS, Chicago, IL, USA) was used for statistical evaluation of the results. Results were evaluated using descriptive statistics and Pearson correlation analysis (two-tailed Pearson correlation coefficient or $r$ ). The paired $t$-test was applied 
to compare numeric data. A $P$ value less than 0.05 was considered significant.

\section{RESULTS}

The mean age of the subjects was $20.3 \pm 0.9$ (range: $19-30$ ) years. Mean penile length in flaccid and stretched states was $9.3 \pm 1.3 \mathrm{~cm}$ (95\% confidence interval (CI): 9.2-9.4 cm) and $13.7 \pm 1.6 \mathrm{~cm}$ (95\% CI: $13.6-$ $13.8 \mathrm{~cm}$ ), respectively $(t=-153, P<0.001)$. Mean flaccid penile length was $4.4 \pm 1.0 \mathrm{~cm}$ which is shorter than mean stretched penile length.

Mean testicular volumes in our study were within the normal range; the mean testicular volume was $22.0 \pm 2.8 \mathrm{~cm}^{3}$ (95\% CI: $21.8-$ $\left.22.1 \mathrm{~cm}^{3}\right)$. The mean volume of right testis was $22.3 \pm 2.9 \mathrm{~cm}^{3}(95 \%$ CI: $\left.22.2-22.5 \mathrm{~cm}^{3}\right)$, and the mean volume of left testis was $21.6 \pm 3.2 \mathrm{~cm}^{3}$ (95\% CI: $\left.21.8-22.1 \mathrm{~cm}^{3}\right)(t=10.4, P<0.001)$ (Table 1$)$. There was a positive correlation between flaccid and stretched penile lengths $(r=0.800, P<0.001)$.

No correlation was found between the mean testicular volume and age, height, weight or BMI $(P>0.05)$. There was a weak positive correlation between penile length and the mean testicular volume $(r=0.143$ for flaccid penile length and $r=0.140$ for stretched penile length, $P<0.001$ for both). Additionally, weak positive correlations were found between penile length (both flaccid and stretched) and height, weight and BMI $(P<0.001)$. Moreover, neither flaccid nor stretched penile length correlated with age $(P=0.871 ; P=0.999)$ (Table 2$)$.

\section{DISCUSSION}

Penis size is a symbol of masculinity, and the perception of having a large penis has been linked to higher self-esteem and power. ${ }^{12}$ Paintings, drawings and other art objects from both Eastern and Western cultures over 1000 years ago attest to this fact. ${ }^{1}$ Today, many men place great importance on the size of their penis in both the erect and the flaccid states. Recently, increasing numbers of men complain about their penis size. ${ }^{2}$ Are these men candidates for 'small penis syndrome'? Possibly, but this is unlikely. Fortunately, most of them have penis sizes within normal limits. ${ }^{2,12}$ In a large Internet-based survey of 52031 heterosexual men and women, most men rated their penis as average sized $(66 \%)$, and only $12 \%$ rated their penis as small. ${ }^{12}$ Science cannot remain silent while the expectations of men are increasing. As a result, more studies have tended to focus on this topic, especially in regard to the physical characteristics of penis size and how it may be influenced by related somatometric parameters.

Measurements of the penile length are generally made during flaccid, stretched and erect states. Relevant literature suggests that measurements of a stretched and flaccid penis provides a reliable estimate of its erect size; hence, there is no need to measure penile length during an erection. ${ }^{10,13}$ In 1899 , the first study about penile length was reported by Loeb, ${ }^{4}$ and the average flaccid penile length was $9.41 \mathrm{~cm}$.

Table 1 Statistics pertaining to the study population

\begin{tabular}{lccrl}
\hline Parameters & Min. & Max. & Mean & s.d. \\
\hline Age (years) & 19 & 30 & 20.3 & 0.9 \\
Height $(\mathrm{cm})$ & 156 & 190 & 174.3 & 4.9 \\
Weight $(\mathrm{kg})$ & 54 & 98 & 68.4 & 6.6 \\
BMI $\left(\mathrm{kg} \mathrm{m}^{-2}\right)$ & 17.5 & 28.6 & 22.5 & 1.1 \\
Flaccid length (cm) & 5.7 & 14 & 9.3 & 1.3 \\
Stretched length $(\mathrm{cm})$ & 9 & 19.1 & 13.7 & 1.6 \\
Right testicular volume $\left(\mathrm{cm}^{3}\right)$ & 10 & 25 & 22.3 & 2.9 \\
Left testicular volume $\left(\mathrm{cm}^{3}\right)$ & 5 & 25 & 21.6 & 3.2 \\
Mean testicular volume $\left(\mathrm{cm}^{3}\right)$ & 11 & 25 & 22 & 2.8 \\
\hline
\end{tabular}

Abbreviation: BMI, body mass index.
In 1942, Schonfeld and Beebe ${ }^{14}$ found the average penile length to be $13.1 \mathrm{~cm}$ in a stretched state. Kinsey et al. ${ }^{15}$ published his hallmark paper about penile length in 1948 . Ponchietti et al. ${ }^{6}$ published the largest study in the literature about penile length in 2001. The first data from a Turkish population were reported in 2002 by Sengezer et al. ${ }^{13}$ The above mentioned studies tried to determine normal penile length. However, the variability among these values reflects the diversity of populations that were studied and the different measurement techniques. To our knowledge, the current study is the fourth largest series in the relevant literature, and the average penile length was found to be similar to the first three largest series, as shown in Table 3.

A few reports in the literature have investigated the relationship between penile length and somatometric parameters. Shah and Christopher ${ }^{5}$ reported no correlation between shoe size and penile length. Ponchietti et al. ${ }^{6}$ found a positive correlation between somotametric parameters (height, weight and BMI) and penile length in their study. In a large Internet-based survey, self-reported penis size was found to be positively correlated with height and negatively correlated with body fat. ${ }^{12}$ In another study, authors reported a significant correlation among age, height, index finger length and penile dimensions, but no significant effect of waist/hip ratio or weight. ${ }^{7}$ In the present study, weak positive correlations were found between penile length (both flaccid and stretched) with height, weight and BMI. Both the international literature and our results demonstrate that there is no exact association between penile length and somatometric parameters. We believe that these results may demonstrate variability among different populations.

Testicular volume measurement is important for assessing testicular function and for estimating spermatogenesis and fertility. ${ }^{16,17}$ Various types of orchidometers, rulers, calipers and ultrasonography can be used to measure testicular volume, and none is superior to another. ${ }^{18,19}$ Prader orchidometry closely correlates with ultrasonographic testicular volume measurements and is considered the standard method when used by experienced examiners. ${ }^{20}$ One of the first objective studies investigating testicular volume, penile length and other somatometric parameters in young men was performed by Spyropoulos et al. ${ }^{8}$ Fifty-two subjects aged 19-38 years were investigated, and penile length was insignificantly and negatively correlated with age, weight, BMI and waist/hip ratio and positively correlated with height. In the same study, a significant positive correlation was reported between penile length and index finger length. Additionally, mean testicular volume had a weakly negative correlation with penile length.

The current study has two main differences from the study of Spyropoulos et al.: ${ }^{8}$ the number of subjects is significantly higher and an orchidometer was used instead of ultrasonography to measure testicular volume. Orchidometry was the preferred measurement technique used in this study because the use of ultrasound in this large populationbased study was not practical or feasible. In this study, a weak positive correlation was found between mean testicular volume (for both testes) and penile length measurement. There was no correlation between the mean testicular volume and other somatometric parameters.

A number of male genital tract organs depend on androgens to promote growth and development. Penile growth before birth, during childhood and during puberty, is strongly influenced by testosterone and is completed by the end of puberty. ${ }^{21}$ In one study, patients who complained about a small penis size were asked when they believed the problem started. Most (62.7\%) reported that their concern began in childhood and continued during teenage years after seeing pornographic images. ${ }^{22}$ In the current study, testicular volume was measured in addition to other somatometric parameters that may be 
Table 2 Pearson's correlation coefficient $(r)$ for assessing the relationship between penile measurements and somatometric parameters

\begin{tabular}{|c|c|c|c|c|c|c|c|c|}
\hline \multirow{2}{*}{ Parameters } & & \multirow{2}{*}{ Age } & \multirow{2}{*}{ Height } & \multirow{2}{*}{ Weight } & \multirow{2}{*}{$B M I$} & \multicolumn{3}{|c|}{ Testicular volume } \\
\hline & & & & & & Right & Left & Mean \\
\hline \multirow[t]{2}{*}{ Flaccid penile length } & $r$ & 0.005 & 0.316 & 0.387 & 0.394 & 0.157 & 0.109 & 0.143 \\
\hline & $P$ & 0.871 & $<0.001$ & $<0.001$ & $<0.001$ & $<0.001$ & $<0.001$ & $<0.001$ \\
\hline \multirow[t]{2}{*}{ Stretched penile length } & $r$ & $<0.001$ & 0.164 & 0.205 & 0.208 & 0.135 & 0.124 & 0.140 \\
\hline & $P$ & 0.999 & $<0.001$ & $<0.001$ & $<0.001$ & $<0.001$ & $<0.001$ & $<0.001$ \\
\hline
\end{tabular}

Abbreviation: BMI, body mass index.

Table 3 Studies about penile length in the current literature

\begin{tabular}{|c|c|c|c|c|c|c|c|}
\hline Publications & $\begin{array}{l}\text { No. of } \\
\text { subject }\end{array}$ & $\begin{array}{c}\text { Age } \\
\text { (years) }\end{array}$ & $\begin{array}{c}\text { Flaccid penile } \\
\text { length }(\mathrm{cm})\end{array}$ & $\begin{array}{l}\text { Stretched penile } \\
\text { length }(\mathrm{cm})\end{array}$ & $\begin{array}{l}\text { Erect length } \\
\quad(\mathrm{cm})\end{array}$ & $\begin{array}{l}\text { Flaccid girth } \\
\quad(\mathrm{cm})\end{array}$ & $\begin{array}{l}\text { Erect girth } \\
(\mathrm{cm})\end{array}$ \\
\hline Loeb, 1899 (reviewed in Ref. 4) & 50 & $17-35$ & 9.41 & NA & NA & NA & NA \\
\hline Schonfeld and Beebe, $1942^{14}$ & 196 & $17-25$ & NA & 13.1 & NA & 8.5 & 15.8 \\
\hline Kinsey et al., $1948^{15}$ & 2270 & $20-59$ & 9.7 & 16.74 & NA & NA & NA \\
\hline Wessells et al., $1996^{10}$ & 80 & $21-82$ & 8.85 & 12.45 & 12.89 & 9.71 & 12.30 \\
\hline Ponchietti et al., $2001^{6}$ & 3300 & $17-19$ & 9.0 & 12.5 & NA & 10 & NA \\
\hline Sengezer et al., $2002^{13}$ & 200 & $20-22$ & 6.8 & 8.9 & 12.7 & NA & NA \\
\hline Spyropoulos et al., $2002^{8}$ & 52 & 19-39 & 7.76 & 12.18 & NA & 8.68 & NA \\
\hline Merhaban et al., $2007^{7}$ & 1500 & $20-40$ & NA & 11.58 & NA & 8.66 & NA \\
\hline Present study & 1132 & $19-30$ & 9.3 & 13.7 & NA & NA & NA \\
\hline
\end{tabular}

Abbreviation: NA, not applicable.

possible confounding factors for penis size. This primarily stems from the fact that penis and testicular growth are the earliest signs of pubertal maturity. ${ }^{21,23}$ Why do different subjects have different penile lengths and testicular volumes? Without a co-investigation of serum androgen levels, the answer to this question cannot be explained fully. We believe that our results may open insight about new studies on this subject.

Size-related concerns should be approached cautiously before surgical planning for penis enlargement, and urologists must know the normal penile length in their specific population. The sample size in the current study is sufficient to be considered a representative and reasonable sample for an equivalent Turkish population. Furthermore, to the best of our knowledge, this is the largest series of healthy, young men measured using Prader orchidometry to analyse the relationship between testicular volume and penile length. The results suggest that somatometric parameters such as height, weight, BMI and testicular volume are related to penile length, even if this relationship is not of clinical significance. We believe that further studies would provide more information about this causal relationship.

\section{AUTHOR CONTRIBUTIONS}

Yılmaz Aslan wrote the main paper and carried out data acquisition and statistical analyses. Ali Atan performed study design and review of the paper, and wrote supplementary information. Ali Ömur Aydın performed data acquisition. Varol Nalçacıoğlu performed data acquisition. Altug Tuncel performed data acquisition and review of the paper. Ateş Kadıoglu performed study design and review of the paper, and supervised the project.

\section{COMPETING FINANCIAL INTERESTS}

The authors declare no competing financial interests.

1 Mattelaer JJ. Ancient Greece and Rome. The Phallus in Art \& Culture. History Office European Association of Urology. 2nd Revised ed. Kortrijk: Pana Editions; 2008. pp8-31.
2 Wylie KR, Eardley I. Penile size and the 'small penis syndrome'. BJU Int 2007; 99: 1449-55.

3 Shamloul R. Treatment of men complaining of short penis. Urology 2007; 65 1183-5.

4 Dillon BE, Chama NB, Honig SC. Penile size and penile enlargement surgery: a review. Int J Impot Res 2008; 20: 519-29.

5 Shah J, Christopher N. Can shoe size predict penile length? BJU Int 2002; 90: 586-7.

6 Ponchietti R, Mondaini N, Bonafè M, di Loro F, Biscioni S et al. Penile length and circumference: a study on 3300 young Italian males. Eur Urol 2001; 39: 183-6.

7 Mehraban D, Salehi M, Zayeri F. Penile size and somatometric parameters among Iranian normal adult men. Int J Import Res 2007; 19: 303-9.

8 Spyropoulos E, Borousas D, Mavrikos S, Dellis A, Bourounis M et al. Size of external genital organs and somatometric parameters among physically normal men younger than 40 years old. Urology 2002; 60: 485-91.

9 Harding R, Golombok SE. Test-retest reliability of the measurement of penile dimensions in a sample of gay men. Arch Sex Behav 2002; 31: 351-7.

10 Wessells $\mathrm{H}$, Lue TF, McAninch JW. Penile length in the flaccid and erect states: guidelines for penile augmentation. J Urol 1996; 156: 995-7.

11 Prader A. Testicular size: assessment and clinical importance. Triangle 1966; 7: 240-3.

12 Lever J, Frederick DA, Peplau LA. Does size matter?: men's and women's views on penis size across the lifespan. Psychol Men Masc2006; 7: 129-43.

13 Sengezer M, Oztürk S, Deveci M. Accurate method for determining functional penile length in Turkish young men. Ann Plast Surg 2002; 48: 381-5.

14 Schonfeld WA, Beebe GW. Normal growth and variation in the male genitalia from birth to maturity. J Urol 1942; 48: 759-77.

15 Kinsey AC, Pomeroy WB, Martin CE. Sexual Behaviour in the Human Male. Philadelphia, , PA: W.B. Saunders Co.; 1948.

16 Takihara H, Cosentino MJ, Sakatoku J, Cockett AT. Significance of testicular size measurement in andrology. II. Correlation of testicular size with testicular function. J Urol 1987; 137: 416-19.

17 Arai T, Kitahara S, Horiuchi S, Sumi S, Yoshida K. Relationship of testicular volume to semen profiles and serum hormone concentrations in infertile Japanese males. Int J Fertil Womens Med 1998; 43: 40-7.

18 Taskinen S, Taavitsainen M, Wikström S. Measurement of testicular volume: comparison of three different methods. J Urol 1996; 155: 930-3.

19 Diamond DA, Paltiel HJ, DiCanzio J, Zurakowski D, Bauer SB. Comparative assessment of pediatric testicular volume: orchidometer versus ultrasound. J Urol 2000; 164: 1111-4.

20 Sakamoto H, Saito K, Ogawa Y, Yoshida H. Testicular volume measurements using prader orchidometer versus ultrasonography in patients with infertility. Urology 2007; 69: 158-62.

21 Seifter J, Ratner A, Sloane D. Concepts in medical physiology. The male reproductive system. Philadelphia, , PA: Lippincott Williams \& Wilkins; 2005. pp605-619.

22 Mondaini N, Gontero P. Idiopatic short penis: myth or reality? BJU Int 2005; 95: 8-9

23 Biro FM, Lucky AW, Huster GA, Morrison JA. Pubertal staging in boys. J Pediatr 1995. 127: $100-2$ 